\title{
Serum level of cytokeratin 19 as a diagnostic and prognostic marker in patients with HCV-related hepatocellular carcinoma
}

Maissa El Raziky ${ }^{1 *}$ (D), Hanan Abdel Hafez ${ }^{1}$, Aisha Elsharkawy ${ }^{1}$, Tarek Ahmed Moneer², Suzan M. EL-Sheikh³, Rabab M. Maher ${ }^{4}$ and Sahar A. Sharaf ${ }^{3}$

\begin{abstract}
Background: The heterogeneous nature of human hepatocellular carcinoma (HCC) impedes both treatment strategies and prognostic predictions. Several markers have been proposed for the diagnosis of HCC. Cytoskeletonassociated proteins have been known as cellular integrators in neoplasm formation. Hepatic progenitor cells are thought to express alpha-fetoprotein (AFP) and hematopoietic as well as biliary markers such as cytokeratin 19 (CK 19) and cytokeratin 7. The aim of this study was to verify the role of serum CK 19 alone or in combination with AFP as a diagnostic marker of HCC and to assess the changes in its levels after ablation of HCV-related HCC to evaluate its role as a predictor marker for recurrence of HCC after ablation. The study was conducted on $102 \mathrm{HCV}$-related cirrhotic patients categorized into three different groups according to the clinical, laboratory, and radiological evaluation: group I-62 patients with early or intermediate HCC who underwent locoregional intervention, group II-20 patients with advanced HCC not fit for any intervention apart from best supportive treatment, and group III-20 cirrhotic patients with no evidence of HCC as proved by two imaging techniques.
\end{abstract}

Results: The mean serum levels of CK 19 were $6.5 \pm 5.7,10.5 \pm 12.5$, and $6.8 \pm 2.8 \mathrm{ng} / \mathrm{ml}$ in groups I, II, and III, respectively, with no significant difference between groups. Sensitivity, specificity, positive, and negative predictive values of combined AFP and human CK 19 at cutoff levels of $25.5 \mathrm{ng} / \mathrm{ml}$ and $6.25 \mathrm{ng} / \mathrm{ml}$ were $93.9 \%, 45 \%, 87.5 \%$, and 64.3\%, respectively. In group I patients, CK 19 levels were comparable in patients with ablated focal lesion and those who did not at baseline; then, it was significantly higher in ablated patients than in patients with residual tumor 1 and 6 months after the intervention.

Conclusions: Combination of both AFP and CK 19 levels could increase the diagnostic accuracy of suspected HCCs. CK 19 levels are good predictors of ablation/recurrence in patients who underwent interventional procedures minimizing the need for follow-up imaging modalities.

Keywords: Cytokeratin 19, Hepatocellular carcinoma, Ablation, Prognostic

\footnotetext{
* Correspondence: maelraziky@yahoo.com

'Department of Endemic Medicine, Faculty of Medicine, Cairo University,

Cairo 11562, Egypt

Full list of author information is available at the end of the article
}

\section{Springer Open}

(-) The Author(s). 2021 Open Access This article is licensed under a Creative Commons Attribution 4.0 International License, which permits use, sharing, adaptation, distribution and reproduction in any medium or format, as long as you give appropriate credit to the original author(s) and the source, provide a link to the Creative Commons licence, and indicate if changes were made. The images or other third party material in this article are included in the article's Creative Commons licence, unless indicated otherwise in a credit line to the material. If material is not included in the article's Creative Commons licence and your intended use is not permitted by statutory regulation or exceeds the permitted use, you will need to obtain permission directly from the copyright holder. To view a copy of this licence, visit http://creativecommons.org/licenses/by/4.0/. 


\section{Background}

The heterogeneous nature of human hepatocellular carcinoma (HCC), which represents a serious health problem being the fifth most common malignancy worldwide, and a common cause of death in patients with chronic liver disease [1], impedes both treatment strategies and prognostic predictions [2].

$\mathrm{HCC}$ emerges through a process of multistep carcinogenesis [3], and its formation is a subject of discussion and controversy. In fact, other than the different etiological factors, an important cause of its heterogeneity may be the cell type of origin. Formerly, it was suggested that preneoplastic lesions arise from mature hepatocytes subjected to neoplastic transformation [4]. Lately, it has also been proposed that a subset of HCC originates from hepatic progenitor cells (HPCs) [5]. This subset of HCC results enriched for genes expressed earlier in fetal hepatoblasts, including some progenitor cell markers. A continuous upregulation of HPCs was also shown in hepatocellular adenoma [6] and dysplastic nodules [7]. HPC activation was demonstrated to be the most relevant liver carcinogenic condition in chronic viral hepatitis, alcoholic, and non-alcoholic fatty liver disease [8].

Several biliary markers have been proposed for HPCs in HCC including cytokeratin 19 (CK 19) and cytokeratin 7 (CK 7). These cells also express alpha-fetoprotein (AFP) and hematopoietic markers (c-kit, CD34) [9-11].

Cytokeratins are the major filament proteins in the liver where any hepatocyte membrane integrity damage causes their release into the circulation [12]. Moreover, CKs have been known as cellular integrators in several neoplastic changes. Characteristic combinations of CKs are expressed by different epithelia according to the organ of origin and differentiation [13]. An experimental model showed that in vitro primary human CK19positive tumor cells showed increased invasiveness and that CK-19 knockdown significantly reduced HCC invasive ability [14].

The aim of this study was to verify the role of serum CK 19 alone or in combination with AFP as a diagnostic marker of HCC, to assess the changes in its levels after ablation of $\mathrm{HCV}$-related $\mathrm{HCC}$, and to evaluate the role of CK 19 as a predictor marker for recurrence of HCC after ablation.

\section{Methods}

This prospective study was conducted on HCV-induced liver cirrhosis patients with and without HCC according to their clinical, laboratory, and radiological evaluation. They were recruited from the HCC unit at National Hepatology and Tropical Medicine Research Institute (NHTMRI) and the Endemic Medicine Department, Faculty of Medicine, Cairo University.

\section{Study participants}

The included groups were as follows: group I: 62 cirrhotic patients, 41 males and 21 females, with a mean age $( \pm \mathrm{SD})$ of $56.6( \pm 5.6)$ years with early HCC defined as single or three nodules each less than $3-\mathrm{cm}$ diameter with Child-Pugh score A or B. These patients underwent one of the locoregional interventions. Group II: 20 cirrhotic patients, 17 males and 3 females, with a mean age $( \pm \mathrm{SD})$ of $55.9( \pm 5.9)$ years, with advanced HCC more than $5 \mathrm{~cm}$, they were not fit for any intervention apart from best supportive treatment according to BCLC classification. Group III: 20 cirrhotic patients, 9 males and 11 females, with a mean age $( \pm$ SD) of $48.1( \pm 4.2)$ years with no evidence of $\mathrm{HCC}$ as proved by two imaging techniques (abdominal ultrasound and triphasic CT with contrast) serving as a control group.

Inclusion criteria were (1) males and females above the age of 18 years; (2) post-HCV chronic liver disease, with positive anti-HCV by third-generation enzymelinked immunosorbent assay (ELISA), detectable serum HCV-RNA by RT PCR and abdominal ultrasonography; and (3) patients in groups I and II with HCC as proved by triphasic CT \pm AFP. Patients with focal lesions other than HCC, history, or evidence of other malignancies; those suffering from any organ failure other than the liver, spontaneous bacterial peritonitis, and hepato-renal syndrome; and previously treated HCC patients were excluded from the study. The protocol was approved by the ethical committee of NHTMRI. After giving an informed consent, the selected patients were subjected to clinical biochemical and imaging assessments; AFP levels were tested by ELISA.

\section{Interventions for patients in group I}

Interventional procedure aiming for $\mathrm{HCC}$ cure based on BCLC staging system and treatment strategy was performed, for patients with stage A HCC: 45 patients underwent radiofrequency ablation (RFA), and 17 patients underwent microwave ablation (MWA) as the tumor had a close relation to a vessel. Follow-up for tumor recurrence and levels of AFP and CK 19 was carried 1 and 6 months after interventions.

\section{Clinical chemistry analysis}

Blood samples were collected and investigated for serum total and direct bilirubin, alanine transaminase (ALT), aspartate transaminase (AST), and albumin on the automated BECKMAN COULTER AU680 autoanalyzer (Beckman Coulter, Inc., 250 S. Kraemer Blvd., Brea, CA 92821, USA).

\section{Quantitative detection of CK 19}

Serum CK 19 levels were assayed in all patients using the double antibody sandwich ELISA technique supplied 
by Sun Red Biotechnology (Shanghai, China). Patients who did not undergo any therapeutic modality were tested only one time at the beginning of this study. Patients who underwent therapeutic interventions were tested for CK 19 at baseline, after 1 month, and 6 months in the follow-up.

\section{Statistical analysis}

Data was analyzed using IBM SPSS advanced statistics version 25 (SPSS Inc., Chicago, IL). Numerical data were expressed as mean and standard deviation or median and range as appropriate. Qualitative data were expressed as frequency and percentage. The chi-square test or Fisher's exact test was used to examine the relation between qualitative variables. For not normally distributed quantitative data, comparison between two groups was done using the Mann-Whitney test. Comparison between 3 groups was done using the KruskalWallis test; then, post hoc "Schefe test" was used for pair-wise comparison based on Kruskal-Wallis distribution. Freidman's test was used to compare 3 consecutive measures of numeric variables followed by the Wilcoxon-signed ranks test used to compare two consecutive measures of numerical variables. The receiver operating characteristic (ROC) curve was used for the prediction of cutoff values of markers. All tests were two-tailed. A p value $<0.05$ was considered significant.

\section{Results}

The comparison of demographic data showed that there was a statistically significant difference between HCC groups and control group in regard to age; the control group was significantly younger than the other $2 \mathrm{HCC}$ groups (p-value $<0.001$ ). Also, the percent of male in group II was significantly higher than controls ( $\mathrm{p}$-value 0.024).

Clinical and abdominal ultrasonography data showed that jaundice, pallor, ascites, and lower limb edema were present in $25 \%, 30 \%, 50 \%$, and $30 \%$, respectively, of the HCC group not fit for intervention but not present in other groups.

The liver biochemical profile of the studied groups showed that there was a significant difference between group II and the other two groups regarding the mean value of albumin and total bilirubin. Albumin in this group was significantly lower than the other two groups $(\mathrm{p}<0.001)$ while total bilirubin was significantly higher. On the other hand, there was no significant difference between all groups regarding the mean value of ALT, AST, and platelet count.

Mean AFP levels were $190.6 \pm 852,951.9 \pm 2323.9$, and $29.3 \pm 44.3 \mathrm{ng} / \mathrm{ml}$ in groups I, II, and III, respectively, with a significant difference between groups ( $\mathrm{p}$ value $<0.001$ ). Regarding the CK 19 levels, there was no significant difference between all groups before any intervention (Table 1).

Using the receiver operating characteristic (ROC) curve, to determine the specificity and sensitivity of human CK 19/AFP alone or combined, the cutoff value of $6.25 \mathrm{ng} / \mathrm{ml}$ and $25.5 \mathrm{ng} / \mathrm{ml}$, respectively, were found to be the most suitable (best cutoff) (Table 2).

Studying the characteristics of the focal lesions (FLs), group I showed solitary FL in $90.3 \%$ of patients, and size was less than $5 \mathrm{~cm}$ in $100 \%$ of this group and mainly seated in the right lobe in $82.3 \%$. On the other hand, the FLs were mainly multiple in $70 \%$ of group II, and the size of lesions in this group was less than $5 \mathrm{~cm}$ in $70 \%$ and bi-lobar in $70 \%$ of cases.

To assess the prognostic value of CK 19 in HCC patients, the outcome of interventions in group I is displayed in Fig. 1 and the relation of these outcomes to changes in CK 19 levels is shown in Table 3. The CK 19 level was comparable in ablated and residual FL patients at baseline and then was significantly higher in ablated patients than in residual tumor 1 and 6 months after the intervention. Follow-up at 1 month of the intervention, CK 19 median level was $2.9 \mathrm{ng} / \mathrm{ml}$ in patients who had no ablation for their FLs compared to it was $15 \mathrm{ng} / \mathrm{ml}$ in patients who had ablation. In the follow-up after 6 months, the CK 19 median level was $5.5 \mathrm{ng} / \mathrm{ml}$ in patients who had recurrence compared to $17 \mathrm{ng} / \mathrm{ml}$ in patients who showed ablation for their focal lesions ( $p$ value $<0.001)$.

\section{Discussion}

Early diagnosis of HCC heavily affects the clinical outcome of patients. The widely accepted serological marker for HCC diagnosis is AFP. However, its diagnostic accuracy is controversial and unsatisfactory because of its low sensitivity. Therefore, there is an increasing demand for the discovery of new HCC-specific biomarkers [15]. Moreover, HCCs expressing the biliary/ HPC marker CK 19 have been linked with a poor prognosis. Therefore, in this study, we addressed the question of the possibility of using CK 19 as a diagnostic and prognostic marker in HCC [16].

It is established that the incidence of HCC increases progressively with advancing age and it is more

Table 1 Levels of CK 19 in the studied patients

\begin{tabular}{lllll}
\hline CK 19 levels (ng/ml) & $\begin{array}{l}\text { Group I } \\
\mathbf{N}=\mathbf{6 2}\end{array}$ & $\begin{array}{l}\text { Group II } \\
\mathbf{N = 2 0}\end{array}$ & $\begin{array}{l}\text { Group III } \\
\mathbf{N = 2 0}\end{array}$ & P value \\
\hline Mean \pm SD & $6.5 \pm 5.7$ & $10.5 \pm 12.5$ & $6.8 \pm 2.8$ & 0.054 \\
Median & 3.2 & 5.4 & 7.2 & \\
Minimum & 1.6 & 2 & 3 & \\
Maximum & 20 & 45 & 11.4 & \\
\hline
\end{tabular}

CK 19 cytokeratin 19 
Table 2 Sensitivity, specificity, positive, and negative predictive values of AFP and CK 19 in studied patients

\begin{tabular}{|c|c|c|c|c|c|}
\hline & Best cutoff & SN & SP & PPV & NPV \\
\hline AFP & $25.5 \mathrm{ng} / \mathrm{ml}$ & $80.5 \%$ & $75 \%$ & $93 \%$ & $48.4 \%$ \\
\hline CK 19 & $6.25 \mathrm{ng} / \mathrm{ml}$ & $63.4 \%$ & $55 \%$ & $85.2 \%$ & $26.8 \%$ \\
\hline Combined AFP and CK 19 & $25.5 \mathrm{ng} / \mathrm{ml}$ and $6.25 \mathrm{ng} / \mathrm{ml}$ & $93.9 \%$ & $45 \%$ & $87.5 \%$ & $64.3 \%$ \\
\hline
\end{tabular}

AFP alpha-fetoprotein, CK 19 cytokeratin 19, SN sensitivity, SP specificity, PPV positive predictive value, NPV negative predictive value

predominant in males [17]. This comes in agreement with the demographic data of the studied patients. In this study, we found a statistically significant difference between the HCC group not fit for intervention (group II) and the other two groups regarding the mean value of albumin and total bilirubin, this could be explained by the fact that lower albumin and higher bilirubin levels are indicators of a higher Child-Pugh score hindering the possibility of interventional therapy.

In the current study, the AFP levels were significantly elevated in the HCC groups compared to the cirrhosis group. This is in agreement with several previous studies $[18,19]$. However, this was not universally agreed [20]. The cutoff value for diagnosis, sensitivity, and specificity showed wide variability among different studies. Our results showed the sensitivity and specificity of serum AFP were $80.5 \%$ and $75 \%$, respectively, with a cutoff value of $25.5 \mathrm{ng} / \mathrm{ml}$ for HCC diagnosis. A study demonstrated that the sensitivity and specificity of AFP at a cutoff value of $10.86 \mathrm{ng} / \mathrm{ml}$ were $75 \%$ and $92 \%$, respectively [21]. Spangenberg et al. reported that at a cutoff value of $20 \mathrm{ng} / \mathrm{ml}$, serum AFP showed $60-80 \%$ sensitivity, although this sensitivity decreases to about $40 \%$ for the detection of small tumors [22]. The use of a higher cutoff value such as $200 \mathrm{ng} / \mathrm{ml}$ drops the sensitivity to $22 \%$ while increases the specificity [23]. Therefore, the use of AFP in clinical practice is limited by the low sensitivity at cutoff values maintaining sufficiently high specificity. These discrepant results warranted exploring the usage of additional biomarkers to improve the diagnostic accuracy.

CK 19 is an HCC-cancer stem cell marker that plays an integral role in carcinogenesis, metastases, and recurrence [24]. In our study, although there was no significant difference in baseline serum CK 19 levels among the three groups, its combination with AFP improved their sensitivity to $93.9 \%$.

To verify the prognostic role of CK 19, we demonstrated that baseline CK 19 levels in group I were significantly lower than 1- and 6-month levels postintervention in those who showed ablation of FLs.

A large meta-analysis was done by Da-wei Sun and his colleagues in 2015 to investigate the association between CK 19 expression in tissue and the prognosis of HCC patients. It included 17 studies with a total of 2943 patients. The results showed that tissue CK 19

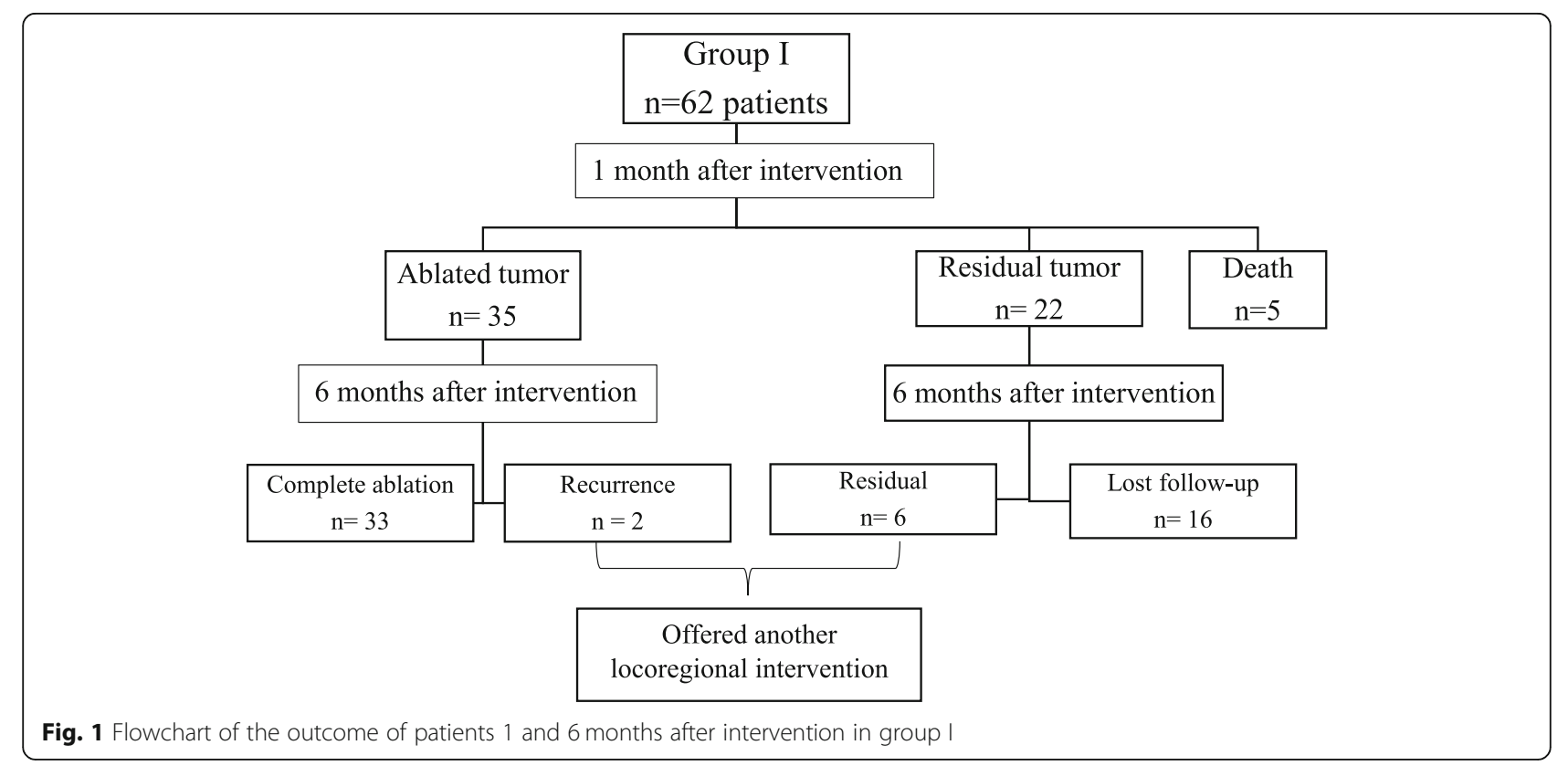


Table 3 Relationship between CK 19 levels and the status of the focal lesions according to the final outcome after 6 months

\begin{tabular}{|c|c|c|c|c|c|c|c|}
\hline & \multicolumn{6}{|c|}{ Focal lesions by $\mathrm{CT}$} & \multirow[b]{3}{*}{$p$ value } \\
\hline & \multicolumn{3}{|c|}{ Residual tumor $(n=8)$} & \multicolumn{3}{|c|}{ Ablated $(n=33)$} & \\
\hline & Median & Minimum & Maximum & Median & Minimum & Maximum & \\
\hline CK 19 before intervention & 3.4 & 1.6 & 16.0 & 3.0 & 1.7 & 20.0 & 0.706 \\
\hline CK 191 month after intervention & 2.9 & 2.0 & 10.0 & 15.0 & 7.8 & 46.0 & $<0.001^{*}$ \\
\hline CK 196 months after intervention & 5.5 & 3.0 & 9.0 & 17.0 & 4.0 & 40.0 & $<0.001^{*}$ \\
\hline$p$ value & 0.223 & & & $<0.001^{*}$ & & & \\
\hline
\end{tabular}

${ }^{*} \mathrm{p}$ value is significant. CK 19 cytokeratin 19

overexpression was significantly associated with poor overall survival rate and early tumor recurrence rate in HCC patients [25].

This difference in results may be attributed to many factors: one of them is the number of candidates that was smaller in our study, and another factor is the method of detection of CK 19 which was by measuring its serum level by ELISA in our study but in other studies was immunohistochemistry of surgically excised tumors or using microarrays. Another factor is a longer period of follow-up in other studies, and this may reveal cases of recurrence or new lesions on long follow-up period.

In our study, we found elevation of serum level of CK 19 after ablation of tumor by single or combined locoregional intervention modalities. These interventions led to damage of tumor cells by necrosis and apoptosis which in turn may have led to the release of CK 19 in serum and this may explain partially our results especially that patients with residual tumors did not show a significant increase of CK 19 levels. This explanation is supported by a study performed by Vanagas and his colleagues who detected apoptosis in the transition zone at a distance of 9$10 \mathrm{~mm}$ from the rim of the necrotic zone $1 \mathrm{~h}$ after local ablation procedure [26]. Another theory for the increased levels of CK 19 as a stemness marker is the occurrence of hypoxia post-intervention [27]. However, more studies are needed to see the effect of liver resection on the level of CK 19 before and after resection.

Limitations of this study include the short duration of and loss of some patients during the follow-up period. The strength of this study is the use of serum CK 19 levels measured by simple ELISA technique instead of the repeatedly reported tissue expression method.

\section{Conclusions}

Measurement of both CK 19 and AFP combined could be a simple, noninvasive way to increase the diagnostic accuracy of suspected HCCs and evaluate treatment response and prognosis in patients with HCC amenable for intervention. Post-ablation elevation of serum CK 19 levels can predict complete HCC ablation before doing imaging modalities.

\section{Abbreviations}

AFP: Alpha-fetoprotein; CK 19: Cytokeratin 19; FL: Focal lesion; HCC: Hepatocellular carcinoma; HPC: Hepatic progenitor cell; MWA: Microwave ablation; RFA: Radiofrequency ablation; ROC: Receiver operating characteristic

\section{Acknowledgements}

Not applicable.

\section{Authors' contributions}

MER, HA, and AE were responsible for the concept, plan of the work, interpretation of results, and final revision. TAM was responsible for patients' inclusion, intervention performance, and follow-up. RMM was responsible for writing the manuscript. SME and SAS were responsible for laboratory work. All authors have read and approved the final manuscript.

\section{Funding}

This research was funded by the authors.

\section{Availability of data and materials}

The datasets used and/or analyzed during the current study are available from the corresponding author on reasonable request.

\section{Declarations}

\section{Ethics approval and consent to participate}

This study was conducted after approval of the ethical committee of the National Hepatology and Tropical Medicine Research Institute. No available reference number. All procedures followed were in accordance with the ethical standards of the responsible committee on human experimentation (institutional and national) and with the Helsinki Declaration of 1975, as revised in 2008 . Written informed consent was obtained from all participants included in the study.

\section{Consent for publication}

Not applicable.

\section{Competing interests}

The authors declare that they have no competing interests.

\section{Author details}

'Department of Endemic Medicine, Faculty of Medicine, Cairo University, Cairo 11562, Egypt. ${ }^{2}$ National Tropical Medicine \& Hepatology Institute, Cairo, Egypt. ${ }^{3}$ Department of Clinical and Chemical Pathology, Faculty of Medicine, Cairo University, Cairo, Egypt. ${ }^{4}$ Fellow of Tropical Medicine, Cairo University Student Hospital, Cairo, Egypt.

Received: 11 March 2021 Accepted: 11 June 2021

Published online: 29 June 2021

References

1. Forner A, Reig M, Bruix J (2018) Hepatocellular carcinoma. Lancet 391(10127):1301-1314. https://doi.org/10.1016/S0140-6736(18)30010-2

2. Thorgeirsson SS, Grisham JW (2002) Molecular pathogenesis of human hepatocellular carcinoma. Nat Genet 31(4):339-346. https://doi.org/10.1038/ ng0802-339 
3. Ho DWH, Lo RCL, Chan LK, Ng IOL (2016) Molecular pathogenesis of hepatocellular carcinoma. Liver Cancer 5(4):290-302. https://doi.org/10.1159/ 000449340

4. Bralet MP, Pichard V, Ferry N (2002) Demonstration of direct lineage between hepatocytes and hepatocellular carcinoma in diethylnitrosaminetreated rats. Hepatology 36(3):623-630. https://doi.org/10.1053/jhep.2002.3 5540

5. Tummala KS, Brandt M, Teijeiro A, Graña O, Schwabe RF, Perna C, Djouder N (2017) Hepatocellular carcinomas originate predominantly from hepatocytes and benign lesions from hepatic progenitor cells. Cell Rep 19(3):584-600. https://doi.org/10.1016/j.celrep.2017.03.059

6. Williams MJ, Clouston AD, Forbes SJ (2014) Links between hepatic fibrosis, ductular reaction, and progenitor cell expansion. Gastroenterology 146(2): 349-356. https://doi.org/10.1053/j.gastro.2013.11.034

7. Libbrecht L, Desmet V, Van Damme B, Roskams T (2000) The immunohistochemical phenotype of dysplastic foci in human liver: correlation with putative progenitor cells. J Hepatol 33(1):76-84. https://doi. org/10.1016/S0168-8278(00)80162-2

8. Rogler CE, Bebawee R, Matarlo J, Locker J, Pattamanuch N, Gupta S, Rogler LE (2017) Triple staining including FOXA2 identifies stem cell lineages undergoing hepatic and biliary differentiation in cirrhotic human liver. J Histochem Cytochem 65(1):33-46. https://doi.org/10.1369/00221554166751 53

9. Lee JS, Heo J, Libbrecht L, Chu IS, Kaposi-Novak P, Calvisi DF, Mikaelyan A, Roberts LR, Demetris AJ, Sun Z, Nevens F, Roskams T, Thorgeirsson SS (2006) A novel prognostic subtype of human hepatocellular carcinoma derived from hepatic progenitor cells. Nat Med 12(4):410-416. https://doi.org/10.103 $8 / \mathrm{nm} 1377$

10. Rhee H, Kim H, Park YN (2020) Clinico-radio-pathological and molecular features of hepatocellular carcinomas with keratin 19 expression. Liver Cancer 9(6):663-681. https://doi.org/10.1159/000510522

11. Roskams T (2003) Progenitor cell involvement in cirrhotic human liver diseases: from controversy to consensus. J Hepatol 39(3):431-434. https:// doi.org/10.1016/50168-8278(03)00333-7

12. Bateman AC, Hübscher SG (2010) Cytokeratin expression as an aid to diagnosis in medical liver biopsies. Histopathology 56(4):415-425. https:// doi.org/10.1111/j.1365-2559.2009.03391.x

13. Turley EA, Veiseh M, Radisky DC, Bissell MJ (2008) Mechanisms of disease: epithelial-mesenchymal transition - does cellular plasticity fuel neoplastic progression? Nat Clin Pract Oncol 5(5):280-290. https://doi.org/10.1038/ ncponc1089

14. Govaere O, Komuta M, Berkers J, Spee B, Janssen C, De Luca F, Katoonizadeh A, Wouters J, Van Kempen LC, Durnez A, Verslype C, De Kock J, Rogiers V, Van Grunsven LA, Topal B, Pirenne J, Vankelecom H, Nevens F, Van Den Oord J, Pinzani M, Roskams T (2014) Keratin 19: a key role player in the invasion of human hepatocellular carcinomas. Gut 63(4):674-685. https://doi.org/10.1136/gutjnl-2012-304351

15. Stefaniuk P, Cianciara J, Wiercinska-Drapalo A (2010) Present and future possibilities for early diagnosis of hepatocellular carcinoma. World J Gastroenterol 16(4):418-424. https://doi.org/10.3748/wjg.v16.i4.418

16. Govaere O, Petz M, Wouters J, Vandewynckel YP, Scott EJ, Topal B, Nevens F, Verslype C, Anstee QM, Van Vlierberghe H, Mikulits W, Roskams T (2017) The PDGFRa-laminin B1-keratin 19 cascade drives tumor progression at the invasive front of human hepatocellular carcinoma. Oncogene 36(47):66056616. https://doi.org/10.1038/onc.2017.260

17. Kew M (2014) Hepatocellular carcinoma: epidemiology and risk factors. Hepatocell Carcinoma 1:115

18. Worland T, Harrison B, Delmenico L, Dowling D (2018) Hepatocellular carcinoma screening utilising serum alpha-fetoprotein measurement and abdominal ultrasound is more effective than ultrasound alone in patients with non-viral cirrhosis. J Gastrointest Cancer 49(4):476-480. https://doi. org/10.1007/s12029-017-0006-y

19. Lersritwimanmaen P, Nimanong S (2018) Hepatocellular carcinoma surveillance: benefit of serum alfa-fetoprotein in real-world practice. Euroasian J Hepato-Gastroenterology 8(1):83-87. https://doi.org/10.5005/jpjournals-10018-1268

20. Han LL, LV Y, Guo H, Ruan ZP, Nan KJ (2014) Implications of biomarkers in human hepatocellular carcinoma pathogenesis and therapy. World J Gastroenterol 20(30):10249-10261. https://doi.org/10.3748/wjg.v20.i30.10249

21. Zhang SY, Lin BD, Li BR (2015) Evaluation of the diagnostic value of alpha--fucosidase, alpha-fetoprotein and thymidine kinase 1 with ROC and logistic regression for hepatocellular carcinoma. FEBS Open Bio 5(1):240-244. https://doi.org/10.1016/j.fob.2015.03.010

22. Spangenberg HC, Thimme R, Blum HE (2006) Serum markers of hepatocellular carcinoma. Semin Liver Dis 26(4):385-390. https://doi.org/10.1 055/s-2006-951606

23. Schütte K, Schulz C, Link A, Malfertheiner P (2015) Current biomarkers for hepatocellular carcinoma: surveillance, diagnosis and prediction of prognosis. World J Hepatol 7(2):139-149. https://doi.org/10.4254/wjh.v7.i2.13

24. Kawai T, Yasuchika K, Ishii T, Katayama H, Yoshitoshi EY, Ogiso S, Kita S, Yasuda K, Fukumitsu K, Mizumoto M, Hatano E, Uemoto S (2015) Keratin 19 a cancer stem cell marker in human hepatocellular carcinoma. Clin Cancer Res 21(13):3081-3091. https://doi.org/10.1158/1078-0432.CCR-14-1936

25. Wei SD, Yi ZY, Dong SX, Guo CY, Qiu W, Ji M, Yue LG (2015) Prognostic value of cytokeratin 19 in hepatocellular carcinoma: a meta-analysis. Clin Chim Acta 448:161-169. https://doi.org/10.1016/j.cca.2015.06.027

26. Vanagas T, Gulbinas A, Sadauskiene I, Dambrauskas Z, Pundzius J, Barauskas $\mathrm{G}$ (2009) Apoptosis is activated in an early period after radiofrequency ablation of liver tissue. Hepatogastroenterology 56(93):1095-1099

27. Nahm JH, Rhee H, Kim H, Yoo JE, Lee JS, Jeon Y, Choi GH, Park YN (2017) Increased expression of stemness markers and altered tumor stroma in hepatocellular carcinoma under TACE-induced hypoxia: a biopsy and resection matched study. Oncotarget 8(59):99359-99371. https://doi.org/1 0.18632 /oncotarget.22078

\section{Publisher's Note}

Springer Nature remains neutral with regard to jurisdictional claims in published maps and institutional affiliations.

\section{Submit your manuscript to a SpringerOpen ${ }^{\circ}$ journal and benefit from:}

- Convenient online submission

- Rigorous peer review

- Open access: articles freely available online

- High visibility within the field

- Retaining the copyright to your article

Submit your next manuscript at $>$ springeropen.com 